\title{
Expression of NGF, Trka and p75 in human cartilage
}

\author{
A. Gigante, C. Bevilacqua, A. Pagnotta, S. Manzotti,, A. Toesca, F. Greco \\ Department of Orthopedics, University of Ancona, Italy; *Department of Anatomy, Catholic University, \\ Rome, Italy
}

(C)2003, European Journal of Histochemistry

Nerve growth factor (NGF) exerts its action through two types of receptor: high-affinity tyrosine kinase A receptor (trkA) and low-affinity p75 receptor. NGF has a neurotrophic role in central and peripheral nervous system development, but there is also clear evidence of its involvement in the developing skeleton. The aim of the present immunohistochemical study was to investigate the expression and distribution of NGF, trkA, and p75 in normal cartilaginous tissues from adult subjects: articular and meniscal cartilage of the knee, cartilage from the epiglottis, and intervertebral disc tissue. Detection of NGF mRNA was also performed by in situ hybridization. Immunoreaction for NGF and the two receptors in articular chondrocytes, chondrocyte-like cells of meniscus and annulus fibrosus, and chondrocytes of the epiglottis demonstrated that they are all expressed in hyaline, fibrous and elastic cartilaginous tissues, suggesting that they could be involved in cartilage physio-pathology.

Key words: cartilage, NGF, NGF receptors, immunohistochemistry, in situ hybridization

Correspondence: Antonio Gigante, MD, Clinica Ortopedica, Università di Ancona, via Tronto 10, 60020 Torrette di Ancona, Italy. Phone: international +39.071 .5963628 .

Fax: international +39.071.2206066.

E-mail: agigante@iol.it

Paper accepted on December 9, 2002

European Journal of Histochemistry 2003; vol 47 issue 4 [Oct-Dec]:339-344
Nerve growth factor (NGF) is a neurotrophic protein responsible for the development and differentiation of sympathetic, sensory and cholinergic neurons ( Levi-Montalcini, 1987). It is produced by neuronal as well as non-neuronal cells such as keratinocytes, smooth muscle cells and lymphocytes (Levi-Montalcini, 1987, Aloe and Tuveri, 1997). NGF exerts its action through two types of receptor, high-affinity tyrosine kinase $A$ receptor (trkA) and low-affinity $p 75$ receptor ( $p 75$ ), which can be activated by all the members of the neurotrophin family (Shu and Mendell, 1999).

NGF has been detected in a variety of skeletal tissues, although its role is still unclear (Aloe et al., 1992; Frenkel et al., 1990; Grills et al.,1997). Increased amounts of NGF have been detected in rheumatoid arthritis synovial fluid (Aloe et al., 1992) consistently with the hypothesis of its involvement in inflammation processes (Lewin et al., 1993). NGF has also been localized in rat periosteal bone progenitor cells, marrow stromal cells, osteoblasts, young osteocytes, endothelial cells of new capillaries and some chondrocytes of the fracture callus (Grills and Schuijers, 1998), suggesting an involvement in fracture healing. Its detection in chick embryonic bone and cartilage has led to hypothesize a role for it in determining the density of sympathetic innervation to the developing skeletal tissue (Frenkel et al., 1990).

Whereas trkA has been detected in bone-forming cells at the fracture callus (Asaumi et al., 2000) and in developing mouse cartilage (Mitsiadis, 1996), p75 has never been studied in any skeletal tissue. Finally, the majority of NGF-responsive cells express both trkA and p75 (Chao, 1994; Miranda et al., 1993). Whereas their co-expression is believed to generate a high-affinity binding site (Chao and Hempstead, 1995), the expression of p75 alone induces NGF-mediated apoptosis in some cells of the central nervous system (Sedel et al., 1999). This investigation was designed to add to the scarce lit- 
erature on NGF and its dual receptor system in skeletal tissue and to establish their expression and distribution in normal mature human cartilage.

\section{Materials and Methods}

\section{Tissues}

We studied autoptic samples of human hyaline, fibrous and elastic mature cartilage. Knee articular cartilage and meniscal tissue and epiglottis cartilage were obtained from 8 subjects aged 19 to 60 years (mean: 41) who had no history of localized or systemic joint disease; intervertebral disc (L1-L2 and L4-L5) samples came from 8 subjects aged 22 to 55 years (mean: 37 ) without a history of back pain. Informed consent to sample collection was obtained from the families.

Of the two specimens obtained from each sample and fixed with $4 \%$ paraformaldehyde for $20 \mathrm{~min}$, one was en block embedded in paraffin, cut into 5 $\mu \mathrm{m}$-thick serial sections, stained with hematoxylineosin, alcian blue, saphranin-0 and Verhoeff's stain and studied with immunohistochemistry; the other was embedded in paraffin and cut into $7 \mu \mathrm{m}$-thick sections that were used for in situ hybridization experiments.

\section{Immunohistochemistry}

Sections were processed using the standard avidin-biotin peroxidase complex procedure (Vectastain Elite kit, Vector Laboratories, CA, USA). Non-specific binding was blocked with $3 \%$ normal goat serum in a phosphate-buffered saline (PBS), $\mathrm{pH} 7.4$, for $30 \mathrm{~min}$ at room temperature; slides were then incubated with primary antibodies overnight at $4^{\circ} \mathrm{C}$. The following antibodies were used: polyclonal anti-NGF (diluted 1:2000; Chemicon International, Inc., CA); monoclonal anti-p75 (NE 20.40; Sigma, Italy), and polyclonal anti-trkA (Santa Cruz Biotechnology, Inc., CA, USA) diluted 1:2000 and 1:200, respectively. Rabbit and mouse immunoglobulins at the same dilutions as the primary antibodies were used as controls. Peroxidase activity was revealed by incubation with $0.05 \%$ 3,3'diaminobenzidine tetrahydrochloride (Sigma) in PBS containing $0.03 \%$ hydrogen peroxide for 5 min at room temperature. Slides were then washed, dehydrated, mounted with Eukitt (0. Kindler GmbH \& Co., Germany) and examined under a Leica Microscope (Cambridge Ltd., UK).

\section{In situ hybridization}

For detection of NGF mRNA, tissue sections were deparaffinized in two changes of xylene, rehydrated in decreasing ethanol concentrations and then treated for $15 \mathrm{~min}$ with $10 \mathrm{mg} / \mathrm{mL}$ Proteinase $\mathrm{K}$ (Sigma) in $50 \mathrm{mM}$ Tris- $\mathrm{HCl}(\mathrm{pH} \mathrm{7.4)}, 10 \mathrm{mM}$ EDTA, $10 \mathrm{mM} \mathrm{NaCl}$. The prehybridization and hybridization steps were performed using the HybriProbe kit (Biognostik, Germany). Sections were allowed to react with the double FluoresceinIso-Thio-Cyanate (FITC)-labeled oligonucleotide probe complementary to the 768-797 base sequence of human NGF mRNA overnight at $30^{\circ}$. They were then rinsed once in sodium chloride-sodium citrate buffer to remove most of the excess probe. Negative controls were performed without the probe, whereas sections from a peripheral nerve were used as positive controls. Method validation was performed using Poly-d(T)-HybriProbe and the Control HybriProbe (antisense probe) with sequence GCT GAC TAC GAC CAG ACA AAG TAC CAT TTG (Biognostik). Finally, mRNA integrity was assessed through detection of the abundant housekeeping gene for $\beta$-actin by a double FITClabeled probe complementary to the 1092-1120 base sequence of human $\beta$-actin mRNA.

Immunodetection of the double FITC probe was performed with a Biognostik detection kit. Sections were incubated for $3 \mathrm{~h}$ with the anti-FITC antibody linked to alkaline phosphatase $(1: 150)$ and then with Nitroblue tetrazolium (NBT)/5-Bromo-4chloro-3-indolylphosphate (BCIP) solution containing levamisole, monitoring color reaction under the microscope. Sections were mounted with Glycergel (Dako, CA, USA) and examined under a Leica microscope.

\section{Results}

\section{Articular cartilage (hyaline cartilage)}

Immunoreactivity for NGF was detected in all the chondrocytes of the three tissue layers, but never in the matrix. Expression of NGF mRNA was observed in all articular chondrocytes (Figure 1). Immunohistochemistry and in situ hybridization revealed no age-related differences in NGF expression nor in its distribution. Immunostaining for trkA (Figure 2) and p75 was observed in the cytoplasm, prevalently in middle layer chondrocytes. 


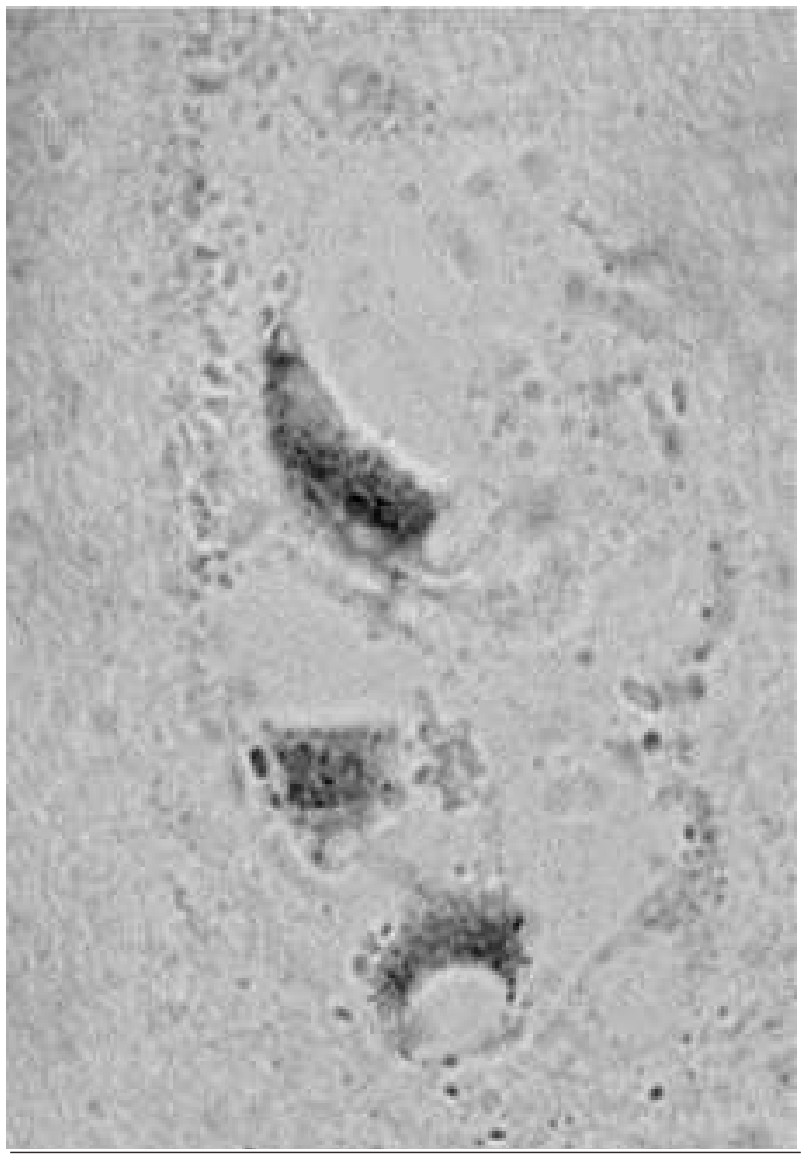

Figure 1. Mature articular cartilage from human knee (femoral condyle): NGF mRNA expression in chondrocytes (1000X).

\section{Meniscal and intervertebral disc tissue (fibrous cartilage)}

Histochemistry revealed two cell morphotypes in meniscal tissue: fusiform fibroblast-like cells mainly in the superficial zone of the menisci, and rounded or polygonal chondrocyte-like cells throughout the remainder of the tissue. NGF mRNA expression and immunostaining for NGF (Figure 3), trkA and p75 were only detected in the latter cells.

In intervertebral disc tissue, we observed rounded chondrocyte-like cells that were more abundant in annulus fibrosus than in nucleus pulposus. These cells stained strongly for NGF (Figure 4), trkA and p75. Some unstained very large polymorphic cells were occasionally observed in nucleus pulposus.

\section{Epiglottis cartilage (elastic cartilage)}

Verhoeff's stain evidenced elastic fibers in the cartilaginous tissue and perichondrium-like tissue in epiglottis samples. The cytoplasm of chondrocytes, but not of the perichondrium-like tissue, stained for NGF, trkA (Figure 5) and p75, without age-related differences.

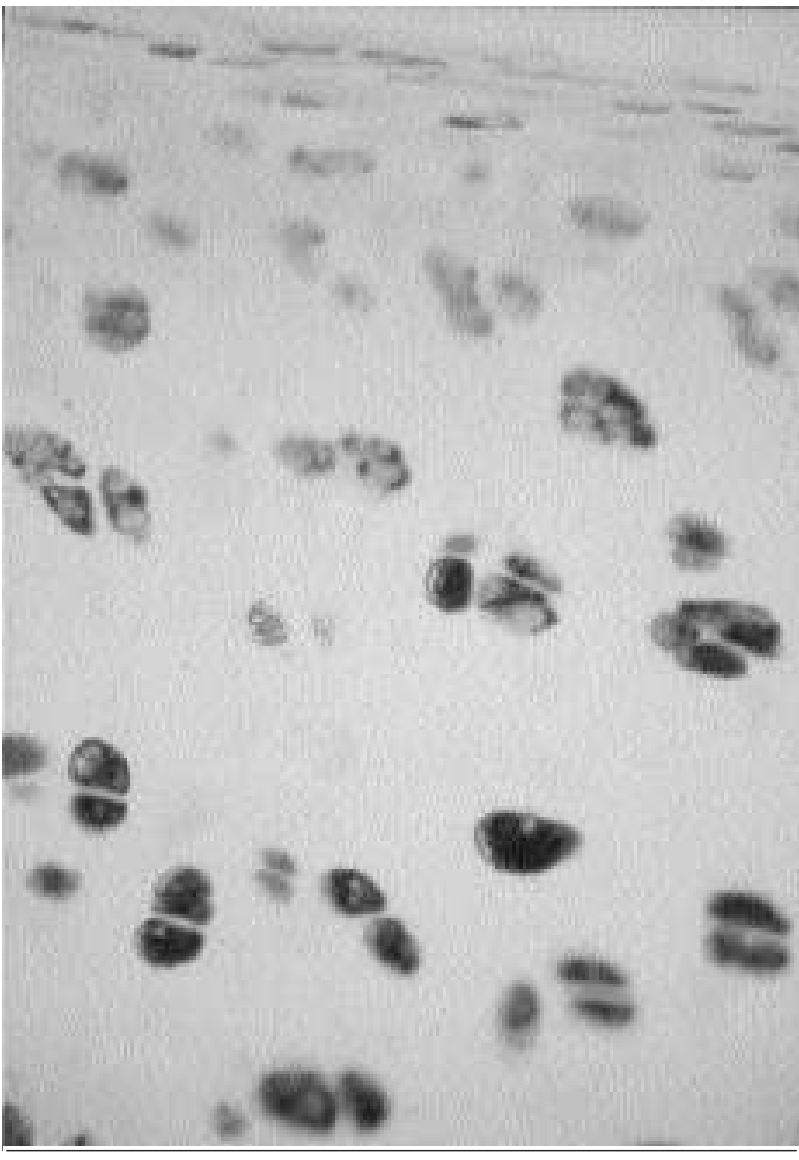

Figure 2. Mature articular cartilage from human knee (femoral condyle): immunostaining for trkA receptor (400x)

\section{Discussion}

Cartilage is a mesoderm-derived tissue whose development requires the apical neuroectoderm ridge, which contributes to the appositional growth of the limb skeleton. The interdependence between neuroectoderm ridge and mesoderm in the developing limb has long been known in animals (Saunders, 1948; Tschumi, 1957) and humans (McCredie, 1976). The presence of nerves in the limb buds (Cameron et al, 1982) and the thalidomide experience (McCredie and Willert, 1999) confirm that the neural crest plays an important role in limb morphogenesis. Thalidomide, a sensory neurotoxin, damages the neural crest or its derivatives, interfering with the development of the limb structures supplied by the injured nerve (McCredie and Willert, 1999). Sensory nerves thus have a trophic function that is separate from sensation: nerve impulses carrying sensation are electrical and centripetal, whereas neurotrophism is believed to act centrifugally through the axoplasmic flow (McCredie and Willert, 1999). 


\section{A. Gigante et al.}
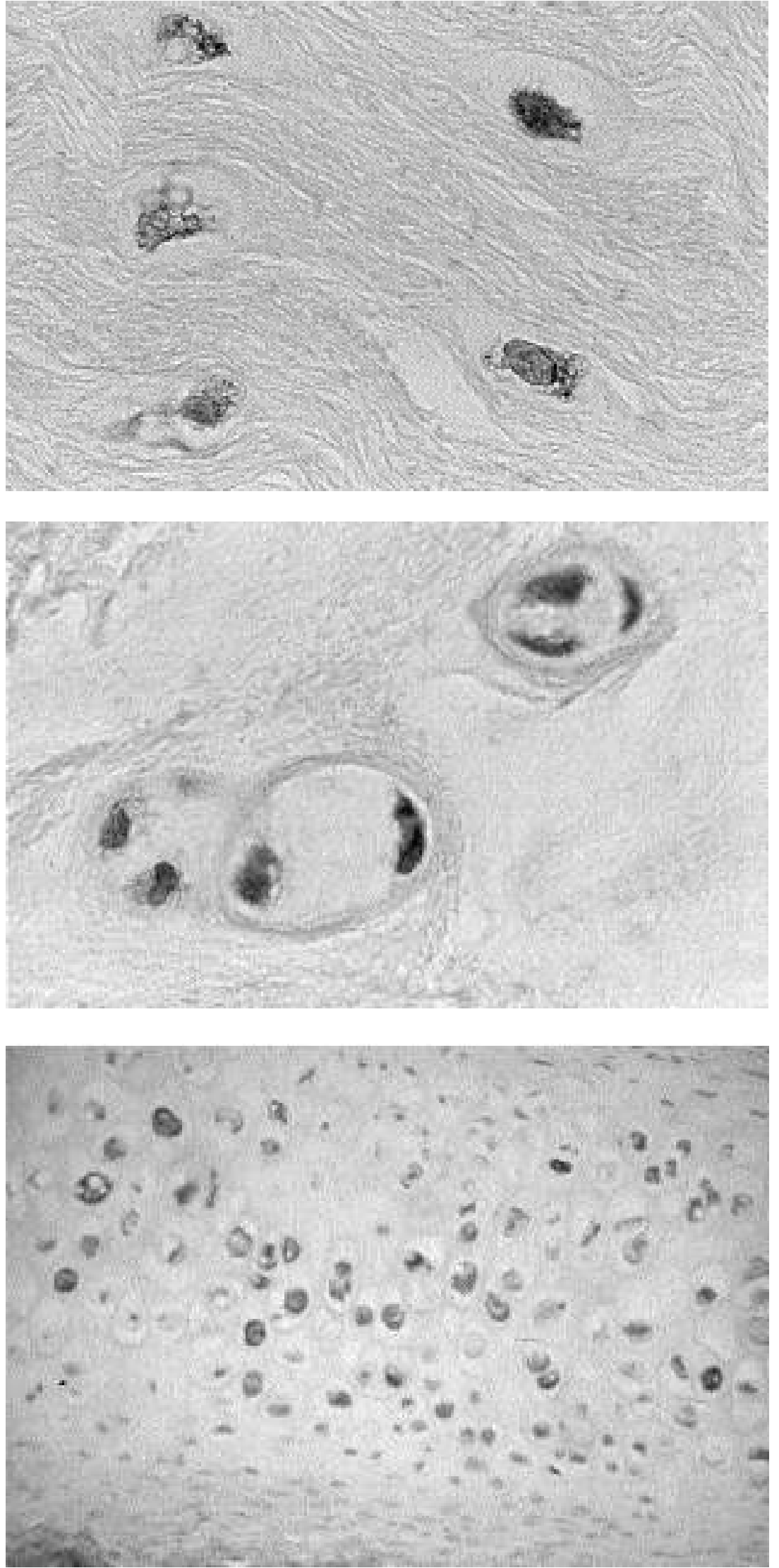

Figure 3. Rounded cells from human knee meniscal tissue staining for anti-NGF antibody (1000x).

Figure 4. Rounded chondrocyte-like cells from human intervertebral disc annulus fibrosus immunostained for anti-NGF antibody (1000x).

Figure 5. Human epiglottis: immunostaining for trkA in the cytoplasm of chondrocytes but not in the perichondrium-like tissue (400x). 
NGF, a member of the neurotrophin family, participates in this neurotrophism by regulating central and peripheral nervous system development, although there is also definite evidence of its involvement in the developing skeleton. NGF (Frenkel et al., 1990) and trkA (Mitsiadis, 1996) have been detected in non-human developing cartilage, and the hypothesis has been advanced (Frenkel et al., 1990) that chondrocytes and osteoblasts may govern embryo innervation by synthesizing and secreting NGF. However, the presence of NGF and its receptor system in human mature cartilage has never been addressed.

We investigated the expression and distribution of NGF and its receptors trkA and p75 in hyaline, fibrous, and elastic human mature cartilage to see whether this tissue produces NGF and might be a target for its action not only in embryonic development but also in later life. Immunohistochemistry and NGF mRNA expression demonstrated that the chondrocytes of different cartilaginous tissues do produce NGF. In particular, all articular chondrocytes were immunoreactive for NGF and its receptors regardless of subject age and tissue layer studied. In the knee menisci they were immunolocalized in rounded chondrocyte-like cells, but they were not observed in fusiform fibroblast-like cells. This patterns of distribution supports the observation by Ghadially and co-workers (1983) of two structural forms of cells in the meniscus: fusiform cells in the superficial zone, and ovoid or polygonal cells in the remainder of the tissue. The latter cells have been designated fibrochondrocytes because, although they have the appearance of chondrocytes, they synthesize a fibrous matrix (Ghadially et al., 1983).

In the annulus fibrosus of the intervertebral disc, chondrocyte-like cells produced NGF and expressed trkA and p75 receptors, but some large cells of nucleus pulposus did not. These data are consistent with previous studies on humans describing at least two phenotypically stable cell populations in the adult intervertebral disc, and with the view that the phenotype of the major population of the annulus is different from the one of the nucleus (Chelberg et al., 1995). Annulus fibrosus cells may be of chondrocytic nature (Poiraudeau et al., 1999; Rufai et al., 1995); similarly, the phenotype of nucleus pulposus cells could be either chondrocytic or notochordal (Poiraudeau et al., 1999). Further studies are clearly necessary to establish these aspects.
Finally, also in elastic cartilage NGF, trkA and p75 were intensely expressed by chondrocytes.

As the co-expression of trkA and p75 generates a high-affinity binding site (Chao and Hempstead, 1995), the immunohistochemical detection of the dual receptor system in human chondrocytes suggests that cartilage may be a target for NGF action.

\section{Acknowledgments}

The authors are grateful to Dr. Silvia Modena for revising the English form.

\section{References}

Aloe $L$, Tuberi MA. Nerve growth factor and autoimmune rheumatic diseases. Clin Exp Rheumatol 1997;15:433-8.

Aloe L, Tuveri, MA, Carcassi U, Levi-Montalcini R. Nerve growth factor in the synovial fluid of patients with chronic arthritis. Arthritis Rheum 1992;35:351-5.

Asaumi, K, Nakanishi, T, Asahara, H, Inoue, H, Takigawa M. Expression of neurotrophins and their receptors (TRK) during fracture healing. Bone 2000;26:625-33.

Cameron J, McCredie J. Innervation of the undifferentiated limb bud in rabbit embryo. J Anat 1982;134:795-808.

Chao MV. The p75 neurotrophin receptor. J Neurobiol 1994;25:137385.

Chao MV, Hempstead BL. P75 and Trk: a two-receptor system. Trends Neurosci 1995;8:321-6.

Chelberg, MK, Banks, GM, Geiger, DF, Oegema TR. Identification of heterogeneous cell populations in normal human intervertebral disc. J Anat 1995;186:43-53.

Frenkel SR Guerra LA, Mitchell OG, Singh IJ. Nerve growth factor in skeletal tissues of the embryonic chick. Cell Tissue Res 1990;260:507-11.

Ghadially FN, Lalonde JM, Wedge JH. Ultrastructure of normal and torn menisci of the human knee joint. J Anat 1983;136:773-91.

Grills BL, Schuijers JA, Ward AR. Topical application of nerve growth factor improves fracture healing in rats.J Orthop Res 1997; 15:235-42.

Grill BL, Schuijers JA. Immunohistochemical localization of nerve growth factor in fractured and unfractured rat bone. Acta Orthop Scand 1998;69:415-9.

Levi-Montalcini R. The nerve growth factor 35 years later. Science 1987;237:1154-62.

Lewin GR, Ritter AM, Mendell LM. Nerve growth factor-induced hyperalgesia in the neonatal and adult rat. $J$ Neurosci $1993 ; 13: 2136-48$

McCredie J. Neural crest defects A neuroanatomic basis for classification of multiple malformations related to phocomelia. J Neurol Sci 1976;28:373-87.

McCredie J, Willert HG. Longitudinal limb deficiencies and the sclerotomes An analysis of 378 dysmelic malformations induced by thalidomide. J Bone Joint Surg 1999;81B:9-23.

Miranda RC, Sohrabji F, Toran-Allerand CD. Neuronal colocalization of $m R N A s$ for neurotrophins and their receptors in the developing central nervous system suggests a potential for autocrine interactions. Proc Natl Acad Sci USA 1993;90:6439-43.

Mitsiadis T. Expression of trk receptors during cartilage differentiation. Ann NY Acad Sci 1996;785:298-300.

Poiraudeau S, Monteiro I, Anract P, Blanchard 0, Revel M, Corvot MT. Phenotypic characteristics of rabbit intervertebral disc cells Comparison with cartilage cells from the same animals. Spine $1999 ; 24: 837-44$. 


\section{A. Gigante et al.}

Rufai A, Benjamin M, Ralphs Jr. The development of fibrocartilage in the rat intervertebral disc. Anat Embryol (Berlin) 1995; 192:53-62.

Saunders JW Jr. The proximo-distal sequence of origin of the parts of the chick wing and the role of the ectoderm. J Exp Zool 1948; 108:363-404.

Sedel F, Béchade C,Triller A. Nerve growth factor (NGF) induces motoneuron apoptosis in rat embryonic spinal cord in vitro Eur $\mathrm{J}$ Neurosci 1999;11:3904-12.

Shu XQ, Mendell LM. Neurotrophins and hyperalgesia Proc Natl Acad Sci USA 1999;96:7693-6.

Tschumi P. The growth of the hindlimb bud of Xenopus laevis and its dependence upon the epidermis. J Anat 1957;91:149-73. 